\title{
TRANSFORMAÇÕES DA PRÁTICA DA ENFERMAGEM NOS ANOS $30^{1}$
}

\author{
CHANGES IN THE PRACTICE OF NURSING IN THE 30'S \\ TRANSFORMACIONES DE LA PRÁCTICA DE ENFERMERIA EN LOS \\ AÑOS 30
}

leda de Alencar Barreira²

\begin{abstract}
RESUMO: Este relatório se insere na linha de pesquisa "A prática profissional e a formação da identidade da enfermeira brasileira", desenvolvida por grupo cadastrado no CNPq e no Núcleo de Pesquisa de História da Enfermagem Brasileira (Nuphebras) da Escola de Enfermagem Anna Nery. Universidade Federal do Rio de Janeiro. Os objetivos do estudo são: relacionar as mudanças institucionais da enfermagem na sociedade brasileira da época à acentuada transição politicoeconômica do pais; analisar os efeitos dessas mudanças institucionais no mercado de trabalho da enfermeira e nas caracteristicas da prática da enfermagem; discutir as novas formas de articulação da enfermagem com outras práticas sociais no interior do campo da saúde. A enfermagem de saúde pública nacional, para acompanhar a ampliação do Estado burocrático, se expandiu e se modificou. Ao mesmo tempo, em um contexto de uma politica de proteção ao trabalhador, desenvolveuse uma politica de incentivo à abertura de hospitais públicos e privados, embora os serviços de enfermagem dessas instituiçōes nāo fossem organizados segundo os padrōes que caracterizavam a enfermagem moderna. Assim, a prática da enfermagem na década de 30 caracteriza-se como o início da transiçāo de um modelo de saúde pủblica urbana para um modelo de assistência hospitalar.
\end{abstract}

PALAVRAS-CHAVE: história da enfermagem, enfermagem de saúde pública, politica de saúde.

\section{INTRODUÇĀO}

Na década de 20 , as circunstâncias favoráveis a uma reforma sanitária haviam ensejado a criação de uma enfermagem de alto padrão no pais, por iniciativa do cientista e sanitarista Carlos Chagas, no interior do aparelho de Estado. No entanto, o discurso médico da época reivindicava, além do direito de intervenção sobre os corpos, também o direito de prescrever as açōes e os comportamentos adequados à mulher e à enfermeira. Esta seria preparada para, a partir da figura idealizada da mulher, amplificar a atuação do médico, renunciando à performance e imitando as qualidades morais do altruismo e, ao mesmo tempo, atendendo aos apelos do progresso e do patriotismo.

Por outro lado, o discurso da Missão Parsons, comissionada pelo governo brasileiro para implantar o modelo anglo-americano de enfermagem na capital da república, era perpassado pela mistica da Fundação Rockfeller, pela ética religiosa do trabalho e da temperança e pelo ideal universal da enfermagem como serviço. Sua organizaçăo tinha uma feição paramilitar e como fundamentos $\circ$ papel civilizador dos Estados Unidos nas

\footnotetext{
' Projeto integrado de pesquisa apoiado pelo CNPq.

${ }^{2}$ Profa Titular EE Anna Nery / Dpto de Enfermagem Fundamental; Membro do Núcleo de Pesquisa de História da Enfermagem Brasileira (Nuphebras); Pesquisador CNPq 1 A.
} 
Américas, no caso, em relaçăo ao movimento sanitário e ao hospital moderno. Não obstante este viés etnocêntrico, e apesar do grande desassossego causado pela irrupção da enfermeira diplomada no campo da saúde, e mesmo na sociedade do Rio de Janeiro, em dez anos (19211931) o trabalho dessa Missão produziu resultados extraordinários, referentes à implantação e reconhecimento de uma escola de enfermeiras de alto padrão, à organização e consolidação de um serviço de enfermeiras de saúde pública e de vários hospitais federais, entre eles o hospital Săo Francisco de Assis. Além disso, ao dar visibilidade à figura da enfermeira diplomada, reforçou no imáginário coletivo a imagem da mulher economicamente emancipada.

A preocupação em garantir a reprodução do discurso da Missão Parsons e a intenção de inserir a escola de enfermagem na universidade, determinaram a necessidade de formar uma liderança nativa. Assim, várias enfermeiras brasileiras foram indicadas para realizar estudos básicos ou pós-graduados nos Estados Unidos, de modo a tornarem-se lidimas sucessoras e interlocutoras preferenciais das enfermeiras dirigentes americanas.

No inicio da década de 30 , o panorama geral do pais modifica-se drasticamente, no contexto do movimento revolucionário liderado por Getúlio Vargas, quando ocorre a emergência de novos atores no cenário nacional, com profundas repercussöes para os rumos da nascente profissäo.

Assim é que os objetivos visados nesta pesquisa foram:

- relacionar as mudanças institucionais da enfermagem na sociedade brasileira da época à acentuada transição politico-econômica do país;

- analisar os efeitos dessas mudanças institucionais no mercado de trabalho da enfermeira e nas caracteristicas da prática da enfermagem;

- discutir as novas formas de articulação da enfermagem com outras práticas sociais no interior do campo da saúde.

O desenvolvimento da pesquisa se fez inicialmente por intermédio da elaboração de subprojetos temáticos, a cargo dos bolsistas que compõe a equipe de pesquisa, com a orientação da coordenadora do projeto. Além disso, contribuiram para o avanço do projeto, alunas de pósgraduação sob a orientação de tese da coordenadora do projeto, e que estudam temas correlatos ao do presente projeto.

A seleção dos documentos escritos se fez a partir do catálogo analitico do Centro de Documentação da EEAN, no qual os documentos estão ordenados por tipo e cronologia, com indicação de sua localização no acervo. Os documentos utilizados foram de caráter oficial: relatórios, regulamentos e normas, bem como correspondências, conferências e discursos. Em uma segunda etapa, a coordenadora do projeto realizou um trabalho de conjunção e complementação de fontes. Neste sentido, foram buscados documentos orais produzidos por membros do Nuphebras no desenvolvimento de outras pesquisas. A partir deste trabalho analítico, procedeu-se à sintese interpretativa acerca do objeto de estudo, que se apresenta a seguir.

\section{EFEITOS DA TRANSIÇÃO POLÍTICO-ECONÔMICA DO PAÍS SOBRE A ENFERMAGEM}

O impacto imediato da assim chamada "revolução de 30" sobre o Serviço de Enfermeiras do DNSP é o comentário inicial do Relatório Anual assinado pela Superintendente interina: "Uma mudança tão radical no governo federal como essa que ocorreu entre 3 e 24 de outubro, naturalmente não podia deixar de produzir efeitos consideráveis no Serviço de Enfermeiras." A seguir ela registra o espírito das enfermeiras frente àqueles dramáticos acontecimentos: "A 3 de outubro, com as noticias do levantamento do estado de Minas Gerais, a primeira reaçăo de muitas enfermeiras, foi o desejo de serem chamadas a prestar serviço de guerra, ou então de se apresentarem como voluntárias". No entanto as autoridades preferiram esfriar os ânimos: "Convocou-se então uma reunião geral, para explicar que, sendo as enfermeiras funcionárias federais, os seus serviços seriam requisitados assim que fossem julgados necessários, havendo de mais a mais, o ministério da Justiça e Negócios Interiores pedido que se continuasse o trabalho o mais normalmente possivel". A Superintendente em exercicio tratou ainda de traduzir 
essa diretriz de acordo com os valores da profissão: "Foi-Ihes também feito sentir que o seu dever de patriotismo requeria que cada uma se mantivesse firme em seu posto, quer na escola de enfermeiras, nos hospitais ou no serviço de saúde pública, preparando-se, ao mesmo tempo, para o caso de serem chamadas a servir". E comenta ainda: "A sua resposta a esta explicação esteve à altura de nossos desejos" ${ }^{\prime \prime}$.

Afinal a participação de enfermeiras e de alunas de enfermagem deu-se tanto no Rio, sede do governo federal, como em Belo Horizonte, um dos focos da rebelião armada, nos seguintes episódios:

- as enfermeiras de saúde pública do Rio de Janeiro realizaram visitas domiciliares às familias dos reservistas do DNSP que tivessem sido recrutados, relatando sua condição financeira e também impedindo que os casos "de tuberculose aberta tivessem que seguir para o campo de luta";

- enfermeiras e alunas da Escola Anna Nery, sob supervisão de Rachel Haddock Lobo, assistente da diretora, prestaram cuidados, no hospital São Francisco de Assis, a dezessete passageiros de um vapor estrangeiro bombardeado pelas fortalezas da barra da baía de Guanabara, que tentava deixar o porto sem autorização;

- a diretora da Escola Anna Nery, Bertha Pullen, que estava em Belo Horizonte quando estourou a revolução, lá organizou hospitais de sangue e instruiu mais de uma centena e meia de "moças de boa familia" em um curso de enfermagem de campanha ${ }^{4}$. (Fraenkel, 1937).

Esse movimento revolucionário assinala o começo da estruturação de um Estado centralizador, caracterizando-se o novo sistema politico pela intervenção nas unidades da federação, mediante a implantação de uma rede de órgãos burocráticos (como o Ministério da Educação e Saúde/ MEC, criado em 1930), e pela inativação dos partidos políticos. (Fausto, 1995).

A Igreja católica foi uma importante base de apoio de Vargas que, por sua vez, atendeu aos interesses da Igreja. Evento emblemático dessa aliança é a inauguração da imagem do Cristo Redentor no alto do Corcovado, diante de quarenta e cinco bispos, vindos de todo o Brasil, e de todos os ministros de Estado, em 12 de outubro de 1931, dia de N.S. Aparecida, padroeira do Brasil. Pouco antes haviam partido as enfermeiras americanas Bertha Pullen e Ethel Parsons. E como previsto, a direção do serviço de enfermeiras de saúde pública, passara às mãos de Edith de Magalhães Fraenkel, a primeira enfermeira brasileira a obter diploma nos Estados Unidos, e a direção da Escola Anna Nery às mãos de Rachel Haddock Lobo, enfermeira brasileira católica, com curso na França, e também com estudos pós-graduados nos Estados Unidos.

Assim, a inauguração do Cristo Redentor como que assinala o fim da Missão Parsons, o inicio da aliança do Estado com a Igreja, e o inicio de uma nova ordem politica e social que se instalava e que determinaria novos rumos para a enfermagem nacional. (Santos, 1996). Logo após a retirada da Missão Parsons, houve uma reação à hegemonia da Escola Anna Nery, tratando-se de atenuar os efeitos de sua instituição como escola oficial padrão ${ }^{5}$ (Batista;Barreira,1997), o que contrariava os interesses das irmãs de caridade, das enfermeiras da Cruz Vermelha, dos enfermeiros do Exército e da Policia Militar, bem como dos enfermeiros práticos.(Rodrigues, 1985).

A crise paulista, instalada desde a ascensão de Vargas ao poder, evolui para a assim chamada revolução constitucionalista, como manifestação de uma tenaz resistência do estado mais forte da federação a um governo centralizador. Rachel Haddock Lobo, diretora da EAN parte do Rio como voluntária para o "front"6 (Batista; Barreira, 1997), liderando um grupo de enfermeiras, entre elas três irmãs de caridade.(Teixeira;Batista;Cavalcanti;Sauthier,1998). Do outro lado da luta, Lais Netto dos Reys, enfermeira do DNSP, então comissionada pela Secretaria de Estado de Educação e Saúde Pública de São Paulo, "organizou para as senhoras da sociedade paulista, na Cruz Vermelha daquele estado, um curso de emergência de três se- 
manas "para atender às necessidades da Revolução de Julho"; e terminado este curso, dirigindo um corpo de voluntárias, assumiu a chefia do hospital de sangue da Cruz Vermelha? ${ }^{7}$. conflito durou cerca de quatro meses e terminou com a vitória militar do governo central, mas com uma vitória politica dos revoltosos, ou seja, a promulgação do novo código eleitoral e a convocação de uma Assembléia Nacional Constituinte. (Madeiros, 1982).

No que se refere à condição feminina, em 1932, é promulgado o Código Eleitoral, aprovando o voto secreto e o voto feminino ${ }^{8}$. A Igreja católica trabalhou também pelo voto feminino universal, uma vez que, em sua estratégia, a mulher era uma aliada indispensável na defesa de suas reivindicações, com relaçăo à familia e à escola.(Horta,1994).

No que se refere à educação, em 1933 surge o manifesto dos Pioneiros da Escola Nova, que constatavam a inexistência no Brasil de uma cultura própria ou mesmo de uma cultura geral e propugnavam por uma escola pública e gratuita, sem distinção de sexo, onde todos teriam educação comum.(Fausto,1995). A luta travada entre as duas facções conjugava aspectos políticos, econômicos e ideológicos. Os defensores das teses católicas foram identificados pelos reformadores como partidários da escola tradicional, que viam na escola pública e gratuita, uma ameaça financeira e, mais ainda, sócio-econômica, pois a escolarizaçāo de todas as camadas sociais ameaçava os privilégios das classes educadas.(Romanelli,1987). O governo Vargas nảo assumiu explicitamente as posições de uma das correntes apontadas, mas mostrou certa inclinação pela corrente católica'. (Fausto, 1995).

Anunciando os novos tempos, a divulgação do curso muda de tom, passando a apresentar a enfermagem como uma das profissões mais importantes em épocas de crise nacional, além de representar para a mulher a oportunidade de "prestar a mais carinhosa de todas as artes da vida"10.(Sauthier, 1996). Mas, a morte prematura de Rachel Haddock Lobo, volta a colocar em jogo antigos interesses, novamente envolvidos na escolha da nova diretora. $E$, apesar de que já houvesse cento e vinte enfermeiras federais formadas pela Escola Anna Nery, sendo dezessete com curso de pós-graduação nos Estados Unidos, a decisão final foi no sentido de que a terceira e última diretora americana, Bertha Pullen, voltasse à direção da casa, para uma segunda gestão, periodo 1934/1938.(Santos, 1996).

O periodo da segunda gestão de Bherta Pullen pode ser definido como de crise politica aberta: 1934 foi marcado por reivindicaçōes operárias e pela fermentação em áreas da classe média; em 1935 ocorreu a "intentona comunista", seguida de intensa repressão e durante 1936 o Congresso aprovou todas as medidas exepcionais solicitadas pelo poder executivo. O Estado Novo, ou seja, um golpe de estado chefiado pelo próprio presidente, foi iniciado em 1937. (Fausto, 1995).

Para contornar a diminuição da procura pelo curso por candidatas do Rio de Janeiro, a propaganda foi ampliada para outros estados da federação, o que deu bons resultados: em março de 1930 foram admitidas dezenove alunas e doze em setembro do mesmo ano.(Sauthier,1996). E a escola continuou a crescer, tanto assim que, em meados de 1937, a diretora da escola comunica ao diretor da Fundação Rockfeller no Brasil, dr Fred Soper, que "the School is admitting on the first of August the largest class it has ever admitted in it's history, in the second semester"11.

A adesão inicial das enfermeiras brasileiras ao modelo anglo-americano de enfermagem se fizera pelo efeito da transformação do poder em carisma, sempre reforçado pelas viagens de estudo aos Estados Unidos. Ao mesmo tempo, ocorreu a progressiva apropriação, pelas enfermeiras nativas, do discurso das enfermeiras americanas, propiciando a elaboração de uma critica e a formação de um espirito de grupo, marcadamente nacionalista que, por um lado, reforça ainda mais o sentimento de dever profissional ligado à colaboração com as autoridades governamentais, mas que, por outro lado, cria um movimento de resistência, que chega a contestar a necessidade da presença de colegas estrangeiras no Brasil (Barreira, 1998). Agora também, que o clima politico nacional era outro, ao assumir a direção dos serviços de enfermagem 
na capital federal, e atuando como representantes do Ministério da Saúde nos estados, governados por interventores federais, várias enfermeiras obtèm o apoio das autoridades sanitárias.(Lima,1968), representadas por médicos amigos da nova ordem revolucionária.(Magalhães,sd).

Entretanto, parece que as maiores dificuldades enfrentadas por essa diretora ocorreram no tempo da reforma dos serviços de saúde federais e subseqüente ingresso da EAN na Universidade do Brasil (UB). Explica ela que ${ }^{12}$ à época da reforma dos serviços de saúde pública federais, em 1934, decidiu-se que a EAN ficaria subordinada ao Departamento de Defesa Sanitária Internacional e da Capital da República, até que fosse transferida para a UB. Não obstante, no ano seguinte, 1935, a escola foi notificada de que na verdade tal subordinação era apenas administrativa, pois tecnicamente continuaria ela a estar subordinada à Superintendência Geral do Serviço de Enfermagem, ou seja, que a escola teria uma dupla subordinação, o que trouxe vários inconvenientes ao seu funcionamento. Em 1936, a dotação de quinze contos de rèis, destinada ao pagamento de professores da EAN foi omitida na lei que fixou a despesa da União para o próximo exercicio, não se resolvendo a situação pelos menos até o mês de maio do ano seguinte ${ }^{13}$. Em 1937, por ocasião da reforma do MES, como a EAN foi incluida no projeto de criação da UB, ficou fora do Departamento de Saúde Pública; entretanto, a parte do projeto de lei referente à reforma da universidade foi vetada pelo presidente e retornou ao Congresso para reestudo, ficando a escola, em caráter precário, ainda no Departamento de Saúde Pública, mas em posição delicada, não tendo ao certo a quem se dirigir.

Não obstante, talvez que essas dificuldades tenham sido acrescidas em muito por circunstâncias desfavoráveis, como os desentendimentos havidos entre Bertha Pullen, ao final de sua primeira gestão, e pessoas que desde então aliadas, agora, durante sua segunda gestão, assumiam posições de primeiro plano, a saber:

- o ex-professor da escola, J.P. Fontenelle, jornalista e médico ilustre ${ }^{14}$, então substituido por solicitação da chefe da Missão que encaminhou exposição de motivos ao diretor geral do DNSP, sobre o desempenho docente insatisfatório daquele sanitarista ${ }^{15}$;

- a ex-assistente da diretora da EAN, Lais Netto dos Reys, a qual havia trabalhado com o dr Fontenelle no centro de saúde de Inhaúma, quando "uma desinteligência entre o diretor do centro e a chefe das enfermeiras obrigara a uma substituição imediata"16 e que, quando chefe do serviço de enfermagem do hospital São Sebastião, se sentiu desautorizada pela diretora da EAN quanto ao descumprimento de suas determinações por uma das enfermeiras-chefes daquele hospital.(Sauthier,1996), e decidiu entrar de férias e em seguida de licença para tratamento de saúde, sendo logo comissionada pelo governo de São Paulo para organizar o serviço de enfermagem de saúde pública daquele estado ${ }^{17}$.

O fato é que, em $1937^{18}$, estas pessoas vêm a assumir posições de destaque: o dr Fontenelle assume o cargo de diretor do Serviço de Saúde Pública do Distrito Federal, a quem a diretora da escola terminou por ficar subordinada, até seu ingresso na UB, em 5 de julho de $1937^{17}$; e d. Lais é comissionada pelo governo para organizar a Escola Carlos Chagas, em Belo Horizonte. (Coelho, 1997).

Neste periodo, sem consulta à diretora, são realizados vários atos contrários aos interesses da escola, como: - transferência de enfermeiras do quadro da escola para outros serviços (cujo percentual aumentou no ano de 1937 de $5,5 \%$ para $17 \%{ }^{19}$ ), inclusive a da chefe da sala de operações do hospital São Francisco de Assis para o Serviço de Enfermagem de Saúde Pública ${ }^{20}$; - exclusão do expediente da escola do serviço de protocolo do referido órgão de saúde pública ${ }^{21}$; - falta de verba para alimentação (previsão de suplementação referente ao último trimestre de $37)^{22}$. No entanto, talvez o fato mais grave, do ponto de vista do desrespeito à autoridade da diretora, tenha sido a designação de uma professora para proceder à inspeção da escola Carlos Chagas, em Belo Horizonte, dirigida por Lais Netto do Reys, para fins de equiparação, pelo ministro Gustavo Capanema, por indicação do diretor geral de educação, sem indicação 
prévia da diretora da escola, como determinava a lei que instituira a Escola Anna Nery como padrão oficial ${ }^{23}$.

A diretora da escola não aceitou passivamente tal situação. Ao contrário, enviou correspondências à superintendente de Enfermagem, Edith Fraenkel, e ao diretor do serviço de saúde pública, dr Fontenelle (cientificando do fato o diretor da Fundação Rockfeller no Brasil), protestando "contra essa designação, como um ato ilegal". E uma vez integrada à UB, solicitou a orientação do reitor que, em resposta, Ihe enviou um lacônico oficio informando-lhe nada poder fazer a respeito. Semanas depois, a professora Maria de Castro Pamphiro, que não havia sido indicada por Bertha Pullen, viajou para Belo Horizonte, sem autorização, apenas dando entrada na secretaria da escola a um comunicado de que estaria indo cumprir a portaria do ministro ${ }^{24}$.

Chama a nossa atenção as divergêngias havidas às mesmas épocas (em 1931 e em 1937) com aquele mesmo médico e com aquela mesma enfermeira. Mas Bertha Pullen não estava sozinha: enquanto se dava a visita de inspeção em Belo Horizonte, ela comunica verbalmente a chegada ao Brasil, dentro de um mês, da diretora de divisảo de enfermagem da Fundação Rockfeller. Ato continuo, consulta a diretora da escola Carlos Chagas sobre seu interesse em receber a visita de miss Tennant, se esta tiver tempo, ao que $d$. Lais responde pela afirmativa. Apesar da aparente pouca prioridade dada à visita à escola Carlos Chagas, esta é a primeira viajem ("por aeroplano de carreira") agendada fora do Rio de Janeiro, estando previstos três dias de duração; ao contrário, a hospedagem oferecida pela diretora dessa escola às duas enfermeiras da Fundação Rockfeller é preterida em favor de um hotel ${ }^{25}$. Deste modo a diretora da EAN parece ter dado mostras de seu poder de inspecionar a escola, ela mesma, dando assim mostra cabal de prestigio, se não com as autoridades brasileiras, certamente com a Fundação Rockfeller, a quem nenhuma autoridade brasileira quereria se dar ao luxo de afrontar.

Assim, mesmo após o seu ingresso na universidade, persistem as dificuldades da escola, inclusive a já alegada falta de verba para alimentaçăo, sem a qual a diretora declara que "será necessário fechar a escola"26. Também continuaram os atritos com a direção da Saúde pública do Distrito Federal. Em 1938, Bertha Pullen encaminha exposição de motivos ao reitor da UB sobre as dificuldades da escola, decorrentes do reduzido número de enfermeiras nos campos de estágio da escola e enfatizando a necessidade de entregar ao diretor do Serviço de Saúde Pública do Distrito Federal a responsabilidade pelo suprimento de enfermeiras para o hospital São Sebastiâo, devendo, a seu ver, a EAN retirar-se do mesmo e reforçar as atividades de ensino e assistência no hospital Săo Francisco de Assis. Caso contrário, declara a diretora "este será mais um passo dado para a destruição da escola Anna Nery"27.

Além disso, a última diretora americana da Escola registra na revista Annaes de Enfermagem a existência de reclamaçōes de médicos, no sentido de que a enfermeira estaria ultrapassando seus limites de atuaçăo.(Pullen,1937). E tanto assim que ela publica um outro artigo na mesma revista intitulado: "Obrigaçōes legais da enfermeira em relação ao médico e ao doente". (Pullen, 1938).

\section{MUDANÇAS NO MERCADO DE TRABALHO DA ENFERMEIRA E NAS CARACTERISTICAS DAPRÁTICA DA ENFERMAGEM}

O novo Departamento Nacional de Saúde (DNS/MEC), que herdou a estrutura sanitária formada ao longo dos anos 20 , veio viabilizar a coordenação de uma politica de saúde de âmbito nacional. No entanto, os recursos e o poder politico investidos na saúde pública são diminuidos em favor da assistência médica individual aos trabalhadores, no interesse do controle da força de trabalho necessária ao processo de industrialização. (Hochman, 1993,Campos, 1994). Esta conjuntura é favorável ao movimento de modernização dos hospitais, que já vinha ocorrendo, 
a partir dos Estados Unidos, desde o inicio do século ${ }^{28}$.

Desde o final da década de 20 , já se haviam tornado evidentes as dificuldades de manter um serviço de visitação permanente às familias pobres da cidade, tanto por resistência delas mesmas, como por relutância das enfermeiras, que muitas vezes preferiam "a posição menos trabalhosa e mais tranqüila de enfermeiras particulares ou de hospitais, abandonando assim o posto indispensável de visitadoras". (Fontenelle,1941). Ao mesmo tempo, devido aos freqüentes surtos epidêmicos (de variola, febre amarela, febre tifóide, sarampo), muitas vezes as enfermeiras do serviço de visitação eram deslocadas por várias semanas para as zonas afetadas, para os hospitais de isolamento do próprio DNSP, para coletividades de menores e até para hospitais militares ${ }^{29}$, o que descontinuava o serviço de visitação domiciliar, responsável pela vigilância epidemiológica e pela educação sanitária das familias pobres.

Por outro lado, as dirigentes de enfermagem no DNSP, preocupadas com a formação de lideres nativas preparadas para atuar no ensino, na organização de serviços de enfermagem, de saúde pública e hospitalares, bem como em todos os campos da assistência de enfermagem, não descuravam daqueles aspectos do preparo das alunas, relacionados tanto à assistência como à administração hospitalares (apesar de suas diplomadas serem absorvidas principalmente pelo DNSP como enfermeiras de saúde pública), como demonstram as assinaturas de revistas especializadas ${ }^{30}$ e também os cursos de pós-graduação realizados pelas enfermeiras brasileiras com bolsa da Fundação Rockfeller ${ }^{31}$.

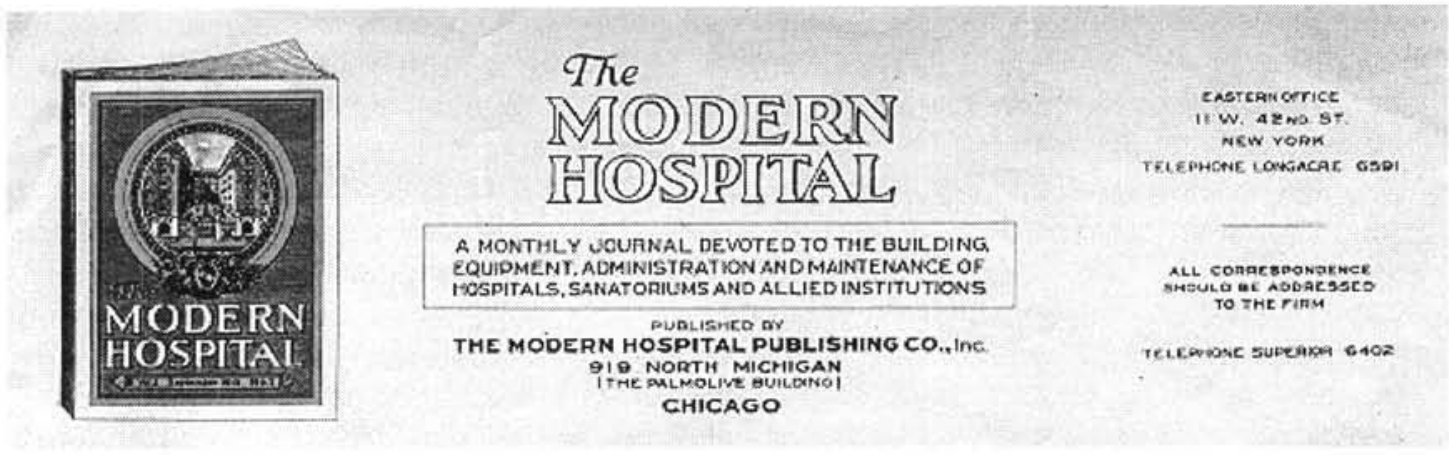

Fig. 1 - A assinatura de revistas americanas especializadas como a "Modern Hospital", ao tempo em que contribuia para um preparo atualizado das futuras enfermeiras, favorecia também a importação de tecnologia hospitalar.

A partir de 1933, de acordo com a nova politica de intervenção do governo central nas unidades da federação, as enfermeiras federais já começaram a ser designadas para colaborar junto aos estados, organizando centros de saúde e treinando visitadoras sanitárias. Também viajavam para organizar escolas e hospitais de ensino, para fazer a verificação das condições de funcionamento das escolas que solicitavam equiparação à Escola Anna Nery, instituída como padrão nacional ao final da Missão Parsons. (Lima, 1952, Lima, 1968).

Ao mesmo tempo, a procura dos serviços de saúde por enfermeiras diplomadas, ou mesmo por vagas na escola de enfermeiras, mostra um crescimento de oportunidades no mercado de trabalho: no ano de 1930 foram matriculadas trinta e uma alunas na Escola Anna Nery, "número muito diminuto em comparação aos pedidos de diplomadas desta escola"(Fraenkel,1937); no entanto, no ano seguinte, a diretora da escola registra a necessidade de aumentar o número de vagas da escola, em virtude dos "pedidos enormes de vagas para alunas, recebidos de todos os estados do pais"32. (Haddock-Lobo,1932). 
No Rio de Janeiro, em 1934, o sanitarista Barros Barreto reformula os serviços federais de saúde pública, criando doze centros de saúde ${ }^{33}$ no Distrito Federal, conforme o modelo implantado no distrito de Inhaúma por Fontenelle, em 1927. No entanto, o governo federal, o maior empregador da nova categoria, passou a não mais absorver as novas turmas de diplomadas pela Escola Ana Néri como enfermeiras de saúde pública federais. Por isto, em 1935, a cidade do Rio de Janeiro contava com apenas 58 enfermeiras de saúde pública, número este considerado como correspondente a apenas $1 / 6$ do necessário. Neste sentido, o então chefe da Inspetoria de Centros de Saúde, JP Fontenelle (que em 1937/38 assumiria a diretoria do Serviço de Saúde Pública do D.F.), envidou esforços no sentido da admissăo de mais sessenta diplomadas, ficando o nủmero de enfermeiras ampliado para 118. (Fontenelle,1941).

Grande parte dos hospitais da cidade pertencia a instituições católicas ${ }^{34}$, que encarregavam mulheres religiosas do serviço de enfermagem, e em relação às quais os médicos em geral preferiam usar de diplomacia, como fez o prof. Miguel Couto que, como presidente da Academia Nacional de Medicina, declarou que, quanto a elas, "que não pediram conselhos, nada há a recomendar ou dissuadir, livre a cada um mandar em sua casa como bem entender ..." 35 .

Também havia serviços particulares (existentes desde antes da vinda da Missão Parsons): Policlinica Geral do Rio de Janeiro, Instituto de Proteção e Assistência à Infância (atual hospital Moncorvo Filho), Pró-Matre (onde estagiaram alunas da EAN), Casa de Saúde do dr Eiras (para doenças mentais), Casa de Saúde São Sebastião, hospitais para estrangeiros (como o Hospital dos Estrangeiros e o Hospital Alemão) que muitas vezes contratavam enfermeiras diplomadas estrangeiras. Com funçōes de assistência social, geralmente em colaboração com entidades filantrópicas, havia os abrigos (Miguel Pereira, Torres Homem e Almeida Magalhães, para tuberculose) e os preventórios (para filhos de mães leprosas ou tuberculosas) na ilha de Paquetá e na praia de Jurujuba (Niterói).

Até meados da década de 30 eram poucos os hospitais públicos existentes na capital federal, como o São Francisco de Assis (hospital geral), o hospicio nacional (de assistência aos psicopatas), o São Sebastião (hospital de isolamento), o de Pronto Socorro (atual Souza Aguiar), o Pedro II (em Santa Cruz), o Arthur Bernardes (infantil), o de Curupaiti (para leprosos) e os hospitais militares (Hospital Central do Exército e Hospital Central da Marinha).

Nos anos 30 são criados os vários institutos de aposentadorias e pensões (IAPS) ${ }^{36}$. Refletindo a politica governamental contencionista, ainda que imbuida da preocupação com a manutenção da força de trabalho, a assistência médica passa a ser vista como atribuição secundária e provisória da previdência ${ }^{37}$, reforçando-se a tendência da compra de serviços médicos de terceiros: hospitais, policlinicas, casas de saúde, e também consultórios, como meio de economizar recursos, e principalmente no que se refere à assistência hospitalar. Tal politica representava um forte incentivo para o investimento de capitais em serviços de saúde com fins lucrativos.

Por iniciativa do prefeito Pedro Ernesto, surgem, a partir de 1933, nas diversas regiōes da cidade, várias unidades hospitalares e para-hospitalares(ESTADO DA GUANABARA, 1972), as quais, no entanto não previam a existência de um serviço de enfermagem de alto padrão: hospital infantil (Vila Isabel), hospital periférico da Gávea, hospital regional periférico de Marechal Hermes, hospital municipal da Penha ${ }^{38}$; e dispensários: de Cascadura (maternidade), de Paquetá, da llha do Governador, do Méier e do Sapêt $\hat{A}^{39}$.

No que se refere ao serviço de enfermagem, em geral, a situação era precária: "as nossas casas de saúde e hospitais de um modo geral não podem estar providos de pessoal competente, mormente de enfermeiros, porque, além de faltar um reservatório onde se supram, pagam ordenados tăo minguados às suas enfermeiras que naturalmente só poderão atrair pessoas pouco capazes e muito necessitadas de ganhar a vida ... O número de doentes é sempre grande e o de enfermeiras, por questões econômicas, sempre diminuto!". (Taborda, 1937). Dentro deste quadro, a nascente demanda pelo trabalho da enfermeira no hospital prendia-se 
primordialmente: à organização do serviço de enfermagem (elaboração e implantação de rotinas de funcionamento e treinamento do pessoal auxiliar); à chefia do serviço de enfermagem e supervisão; e à organização de salas de operação.

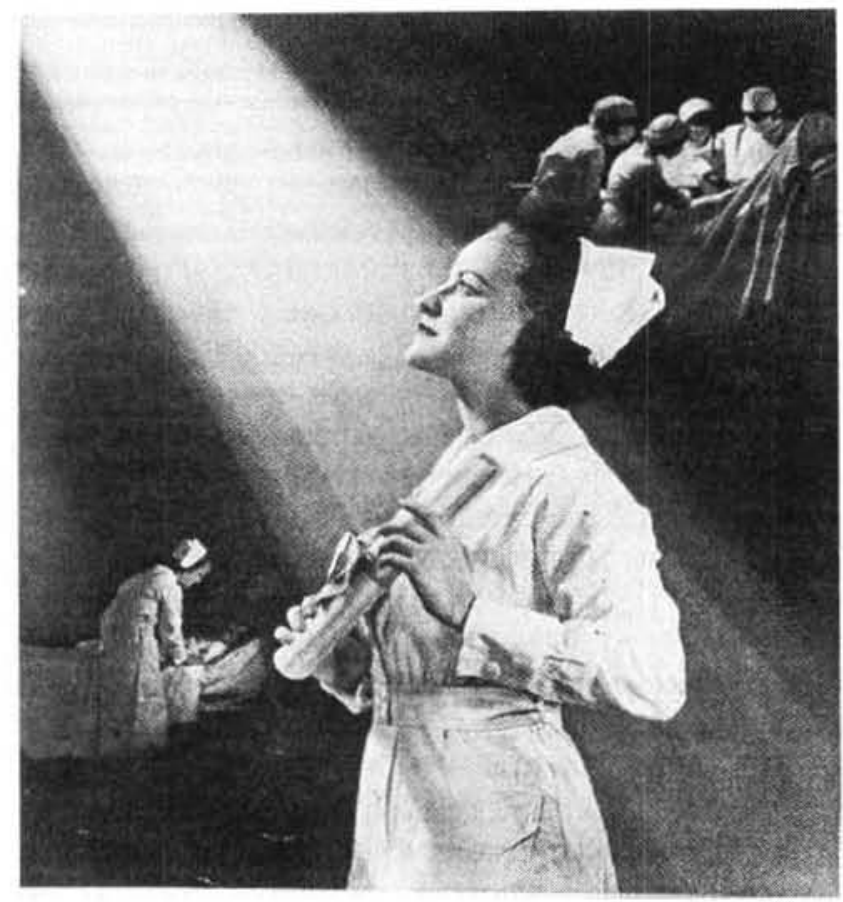

Fig. 2 - O avanço do "hospital moderno"fez com que ganhe força no imaginário coletivo a figura da enfermeira diplomada como "anjo branco", difundida pelo laboratório Johnson \& Johnson *0

Sintomaticamente, a revista "Annaes de Enfermagem" publica vários artigos, inclusive o intitulado "Pontos essenciais para um serviço de enfermagem hospitalar adequado", de autoria de Bertha Pullen, no qual ela trata dos critérios a serem adotados nos cálculos para a previsão do pessoal de enfermagem, com base nas caracteristicas da clientela a ser atendida e tempo médio de enfermagem necessário por leito.(Pullen,1938). Neste periodo surge a primeira revista de enfermagem brasileira, como órgão da associação de classe, e da qual Rachel Haddock Lobo foi fundadora e redatora-chefe (1932-1933), os "Annaes de Enfermagem". Também são escritos os primeiros manuais de enfermagem, por Zaira Cintra Vidal, diplomada da turma pioneira da Escola Anna Nery: "Técnica de Enfermagem" (1933), "Drogas e soluções" (1934) e, mais tarde, "Técnica de Ataduras" (1938). 


\section{NOVAS FORMAS DE ARTICULAÇÃO COM OUTRAS PRÁTICAS SOCIAIS NO INTERIOR DO CAMPO DA SAÚDE}

Do ponto de vista da inserção na sociedade, a enfermeira diplomada permanecia entre a freira e a dama da sociedade dedicada à filantropia, estando as três, embora concorrentes, sob $a$ influência ou sob o controle da Igreja ${ }^{41}$. No entanto, nem as religiosas, nem as damas da sociedade, que executavam ambas trabalho não remunerado, mas competitivo ao da enfermeira, poderiam se constituir em figuras a serem por elas imitadas. De outro modo, o voto de pobreza das irmās e a dependência econômica das casadas, deixavam sozinha a enfermeira profissional, para falar em nome de sua carreira e das recompensas materiais a ela devidas.(Barreira,1997).

Sendo as enfermeiras quase sempre funcionárias do governo, não chega a surpreender que reproduzissem o discurso oficial, como registram os "Annaes de Enfermagem". A incorporação do discurso médico pelas enfermeiras era favorecido por sua autoridade de homens, aos quais é atribuida uma distinção natural, "bastando-Ihes ser o que são para serem o que é preciso ser" (Fonseca, 1996, p.69), mas também por seu prestigio de pessoas bem colocadas socialmente, muitas vezes sábios ou cientistas, cujo respaldo politico, ademais, Ihes era de todo necessário. E se tornava tanto mais fácil pela presença dos médicos nos espaços profissionais, onde os ideais e aspirações de classe média reproduziam-se sob a forma de uma ética profissional e da observância de uma etiqueta institucional.(Barreira, 1997).

Não obstante, as lideranças da enfermagem participavam de várias entidades de promoção da mulher e de assistência social como a Associação Cristã Feminina ${ }^{42}$ (ACF), a Federação Brasileira pelo Progresso Feminino ${ }^{43}$ (FBPF) e o Serviço de Obras Sociais (SOS), este fundado por Edith de Magalhães Fraenkel em 1934, quando Superintendente do Serviço de Enfermeiras de Saúde Pública, como meio de tentar atender aquelas necessidades que tanto dificultavamo trabalho das enfermeiras daquele órgăo ${ }^{44}$.

Edith Fraenkel, por entender que o trabalho da enfermeira de saúde pública e da assistente social se completavam, liderou o movimento pela profissionalização da visitadora social, formada em escolas de serviço social, conceituado como "a atividade de ajudar os outros a se ajudarem a si próprios".(Fraenkel, 1937).. Outros artigos também foram publicados na revista Annaes de Enfermagem, apresentando o serviço social como substituto da filantropia caritativa, considerada como aviltante à dignidade humana(Taborda,1937) e adiantando um "plano de uma Escola de Serviço Social e suas finalidades(Fonseca, 1937).

Assim é que quando finalmente, no dia 5 de julho de 1937, a Escola Anna Nery logra finalmente ingressar na universidade ${ }^{45}$, inclusive com a ajuda do movimento de mulheres ${ }^{46}$, a lei que determinava tal providência ${ }^{47}$, criava ao mesmo tempo um curso de Serviço Social junto à Escola, o que foi motivo de grande descontentamento para a diretora Bertha Pullen, que envidara todos os esforços para reverter o conteúdo do respectivo projeto de lei ${ }^{48}$.

Já no mês seguinte a escola é convidada pelo Secretário Geral de Segurança Nacional, a "emprestar o brilho de sua participação na Parada da Mocidade e da Raça", que já vinha se realizando desde o ano anterior, "como uma prova das mais vibrantes comemoraçōes da Semana do Brasil". Bertha Pullen tenta isentar a escola desta obrigação, alegando que as alunas "prestam serviço hospitalar sem interrupção", mas o reitor não concordou ${ }^{49} \mathrm{com}$ a recusa da EAN, opinando ser conveniente o comparecimento de "um pequeno grupo de alunas, cuja organizaçāo não prejudique o serviço hospitalar do dia". E o reitor não poderia mesmo concordar com a opinião da diretora, já que, no mesmo 5 de julho p.p., em nome da universidade, havia outorgado ao presidente Vargas o titulo de doutor honoris causa ${ }^{50}$.

Com a partida de Bertha Pullen, em 1938, é nomeada diretora uma brasileira, católica convicta, exatamente Lais Netto dos Reys, que tantos problemas Ihe causara. A partir dai estreita-se a associação entre as enfermeiras católicas e a alta hierarquia da Igreja, a qual era bastante favorecida pela aliança desta com o governo Vargas(Barreira,sd). Como evento 
emblemático dessa conjuntura surge a Escola Carlos Chagas, em Belo Horizonte, em 1933, a primeira a formar religiosas no pais, organizada por Lais Netto dos Reys, e por ela dirigida até $1938^{51}$, quando a mesma assume a direção da Escola Anna Nery, que recebe então doze alunas religiosas, após autorização do cardeal arcebispo do Rio de Janeiro, d. Sebastiăo Leme, e para as quais a diretora, considerando que a presença de alunas-religiosas elevava sobremodo - conceito da escola na sociedade, providencia clausura e capela nas dependências do internato.(Teixeira, 1998).

Os efeitos desses laços se faziam sentir no regime de vida do internato, que com isto sofreu notável alteração. No entanto, tal clima não parecia incomodar a maioria das alunas, elas também católicas e de familias católicas. Ao contrário, esta faceta pareceria acrescentar força à personalidade da diretora. Uma aluna de religião protestante poderia se sentir bem e admirá-la. E mesmo uma aluna relacionada com militantes do partido comunista não escapava do poder de sedução da diretora. Entretanto, as alianças da diretora, com a Igreja e com o governo, possibilitaram-lhe o poder de não ter que transigir em relação à sua autoridade ${ }^{52}$.

\section{CONSIDERAÇÖES FINAIS}

A assim chamada "revolução de 30" teve um forte impacto, tanto sobre o Serviço de Enfermeiras de Saúde Pública do Distrito Federal como sobre a Escola Anna Nery, que acompanham o movimento centralizador do governo federal, mas também são afetados pela reforma administrativa que criou o Ministério da Educação e Saúde.

Com o término da Missão Parsons, em 1931, estando já a Escola Anna Nery instituida como "padrāo oficial", as diretoras Rachel Haddock Lobo e Bertha Pullen enfrentam dificuldades não só para fazer ver e fazer valer os direitos da escola e das enfermeiras por ela diplomadas, mas também, principalmente no que se refere à segunda, para obter o apoio e até mesmo para ter suas diretrizes acatadas pelas próprias enfermeiras.

A enfermagem de saúde pública nacional, para acompanhar a ampliação do Estado burocrático, se expandiu e se modificou. Ao mesmo tempo, em um contexto de uma política de proteção ao trabalhador, desenvolveu-se uma politica de incentivo à abertura de hospitais e clínicas privadas, como prestadoras de serviços remunerados. E apesar da criaçăo de vários hospitais públicos, na assim chamada reforma Pedro Ernesto, os serviços de enfermagem dessas instituiçōes não eram organizados segundo os padrōes que caracterizavam o exercicio da enfermagem moderna.

Deste modo, ao tempo em que a imagem da enfermeira brasileira como enfermeira de saúde pública começava a perder sua nitidez, os serviços de enfermagem hospitalares não acompanharam no periodo o ritmo do desenvolvimento da enfermagem moderna em nossa sociedade.

Assim, o exercício da enfermagem na década de 30 caracteriza-se como o início de uma transição de um modelo de prática de saúde pública urbana para um modelo de assistência hospitalar.

Já ao final da década, a luta pelo ingresso da Escola Anna Nery na Universidade do Brasil, revigora a antiga aliança de enfermeiras brasileiras com lideres do movimento pelos direitos civis das mulheres e pela profissionalização do serviço social em nossa sociedade. $E$ uma vez inserida na universidade a escola é chamada a participar de manifestaçöes patrióticas e de culto à personalidade de Vargas, já no início do periodo ditatorial.

Por outro lado, com a partida da última diretora americana, e diante da aliança do governo Vargas com a Igreja Católica, assume a direção da escola uma "católica convicta", 
Laís Netto dos Reys, que com essa já vinha mantendo estreitos laços de colaboração no campo do ensino da enfermagem. No entanto a personalidade carismática da nova diretora viria atrair também alunas de outras religiões e de outras convicçōes politicas.

\section{NOTASDE RODAPÉ}

${ }^{3}$ Relatório Narrativo do Serviço de Enfermeiras do Departamento Nacional de Saúde Pública para o ano findo em 31 de dezembro de 1930. Centro de Documentação da EEAN, cx 27, doc.169, 1930.

4 o decreto 21141 de 10/3/32 aprovou a organização do quadro de enfermeiros do exército e criou o curso de enfermeiros da Escola de Saúde do Exército, cujos diplomas eram registrados no Ministério da Guerra; e o decreto 22257 de 26/12/32 conferiu às irmãs de caridade direitos iguais aos das enfermeiras diplomadas (somente em 1955 as irmãs viriam a ser enquadradas como enfermeiras práticas ou como práticas de enfermagem).

${ }^{5}$ o decreto 21141 de 10/3/32 aprovou a organizaçäo do quadro de enfermeiros do exército e criou o curso de enfermeiros da Escola de Saúde do Exército, cujos diplomas eram registrados no Ministério da Guerra; e o decreto 22257 de 26/12/32 conferiu às irmãs de caridade direitos iguais aos das enfermeiras diplomadas (somente em 1955 as irmãs viriam a ser enquadradas como enfermeiras práticas ou como práticas de enfermagem).

${ }^{6}$ Centro de Documentação da EEAN. Relatório Narrativo da Divisão de Instrução. Setembro de 1932, p.1-2. dos Reys.

7 Centro de Documentação da EEAN. Série diretoras e outras autoridades. Pasta Lais Netto

${ }^{8}$ decreto 21 076, de 24/2/32,

${ }^{9}$ sobretudo na medida em que o sistema politico se fechava.

10 Centro de Documentaçäo da EEAn, cx 24, doc.49, 1930.

" Centro de Documentação da EEAN, cx 64, doc.93, 1937.

12 apesar da criaçāo do MES em 1930, a reforma do Departamento de Saúde Pública só veio a ocorrer quatro anos depois, por força do decreto 24814 , de 14 de julho de 1934 .

${ }^{13}$ Centro de Documentação da EEAN, cx 64, doc.93, 1937.

${ }_{14}$ que em 1929 e em 1930 publicou artigos contra o diretor do DNSP, prof. Clementino Fraga, no jormal "A Noite", tendo como alvos preferenciais as enfermeiras dirigentes americanas, às quais atribuia a responsabilidade pela evasäo de alunas e enfermeiras, devida ao regime disciplinar por elas adotado e qualificado de extremamente rigido e desumano. Centro de Documentaçäo da EEAN, cx 23, doc. 329, 1929; cx 27, doc. $174,1930$.

${ }^{15}$ Centro de Documentaçāo da EEAN, cx 33, doc. 163, 1931.

${ }^{16}$ Centro de Documentação da EEAN. Série Diretoras e outras personalidades. Pasta Lais Netto dos Reys.

17 Centro de Documentação da EEAN. Relatório Narrativo, Fevereiro de 1931, p.2-3.

${ }^{18}$ Centro de Documentação da EEAN, cx 66, doc.136, 1937.

19 Centro de Documentação da EEAN, cx 67, doc.9, 1937.

${ }^{20}$ Centro de Documentação, cx 64, doc.96, 1937.

${ }^{21}$ Centro de Documentação da EEAN, cx 66, doc.136, 1937.

${ }^{22}$ Centro de Documentaçäo da EEAN, cx 65, doc.118, 1937.

${ }^{23}$ Centro de Documentação da EEAN, cx 63, doc.70 e cx 64, doc.85, 1937.

${ }^{24}$ Centro de Documentação da EEAN, cx 64, doc. 85, 1937.

${ }^{25}$ Centro de Documentação da EEAN, cx 64, doc.85, 1937.

${ }^{26}$ Centro de Documentação da EEAN, cx 65, doc.118, 1937.

${ }^{27}$ Centro de Documentação da EEAN, cx 67, doc.9, 1938.

${ }^{28} \mathrm{O} 1^{\circ}$ Congresso Hospitalar Internacional, realizou-se em Atlantic City, NJ / EUA, em 1929. Centro de Documentaçäo da EEAN, cx 19, doc.108, 1929.

29 Relatórios Narrativos do Serviço de Enfermeiras do DNSP, referentes à década de 30 , elaborados pela Superintendente Geral. Centro de Documentação da EEAN.

${ }^{30}$ por exemplo: Public Health Nursing. American Joumal of Nursing e Modern Hospital, cujas assinaturas eram renovadas anualmente pela Fundaçẩo Rockfeller. Centro de Documentação da EEAN, cx21, doc.207, 1929.

${ }^{31}$ principalmente no Philadelphia General Hospital, cuja Escola de enfermagem, dirigida por 
Lillian Clayton (também superintendente do Serviço de Enfermagem do hospital) fora fundada em 1864, pela enfermeira inglesa Alice Fisher, ex-aluna de Florence Nightingale (Carvalho, 1976, p.14; Cook, 1942, p.465)

32 Justificativa que acompanha o projeto de orçamento da Escola Anna Nery para o ano de 1932. Centro de Documentação da EEAN, cx 31, doc.107, 1931.

${ }^{3} 01^{\circ} \mathrm{em}$ Botafogo, o $2^{\circ}$ no Largo do Machado, o $3^{\circ}, 04^{\circ}$ e o $5^{\circ}$ no Centro (na rua do Rezende, na rua Camerino e na praça da Bandeira), o $6^{\circ}$ na praça Sans Peña; o $7^{\circ}$ na praça Engenho Novo, o $8^{\circ} \mathrm{em}$ Inhauma, o $9^{\circ} \mathrm{em}$ Jacarepaguá, o $10^{\circ}$ na Penha, o $11^{\circ} \mathrm{em}$ Madureira e o $12^{\circ} \mathrm{em}$ Bangú. Centro de Documentação da EEAN, cx50, doc.212, 1935

${ }^{34}$ como a Santa Casa da Misericórdia e as ordens: Terceira dos Minimos de São Francisco de Paula, Terceira de N.S. do Monte do Carmo e Terceira de São Francisco da Penitência. Fonte: Ribeiro, Lourival, 1992, p.207-208 (25).

${ }^{35}$ discurso proferido na Academia Nacional de Medicina. Jomal do Comércio, s/d. Centro de Documentação da EEAN/UFRJ, cx 45, doc.11, 1935.

${ }^{36}$ em substituição às antigas caixas de aposentadorias (CAPs), criadas na década de 20, a saber: IAPMaritimos (1933), IAPBancários (1934), IAPIndustriários (1936), IAPTEC / Transportes e Cargas e IPASE (Instituto de Previdência e Assistência aos Servidores do Estado (ambos em 1938) e o IAPComerciários (já em 1940).

${ }^{37}$ ao contrário do que ocorria na década de 20 , quando a assistência médica era pensada como uma atribuiçāo central, obrigatória e permanente das instituiçōes previdenciárias (Oliveira; Teixeira, 1986, p.90).

${ }^{38}$ denominaçōes atuais: hospital Jesus, Miguel Couto, Carlos Chagas e Getúlio Vargas, respectivamente.

${ }^{39}$ denominações atuais maternidade Herculano Pinheiro, hospital Manoel Arthur Villa Boim. hospital Paulino Wermeck, hospital Salgado Filho e maternidade Carmela Dutra, respectivamente.

${ }^{40}$ Fonte: Reverby, Susan M. Ordered to Care: the dilemma of American Nursing (1850-1945) Cambridge University Press, USA, 1987, p.91.

4l tal influência determinou o movimento pela criação de uma Associaçāo de Enfermeiras Católicas, que provocou polêmica entre as próprias enfermeiras católicas, posto que, tendo que se submeter ao Código do Direito Canônico, feria o ideal de serviço universal da enfermeira, além de induzir a enfermeira católica a "trabalhar pela santificação e assistência religiosa dos enfermos sob seus cuidados", bem como para "... que os enfermos, especialmente em perigo próximo de vida, se disponham a receber os sacramentos ..." Centro de Documentaçăo da EEAN, cx 25, doc.53, 1930).

42 na qual Rachel Haddock Lobo foi secretaria interina e responsável pelos contatos com "enfermeiras e professoras". Centro de Documentação da EEAN, cx 35, doc.3, 1932.

${ }^{43}$ Em julho de 1930 a FBPF ofereceu uma recepção às enfermeiras diplomadas. Em outubro seguinte, uma comissäo liderada por Bertha Lutz visitou a escola, sendo recebida por Rachel Haddock Lobo (diretora interina) e sua assistente Sylvia Maranhāo. Centro de Documentação da EEAN, cx 29, doc. 304 e cx 27, doc.170, 1930. Anos mais tarde, atendendo à presidente da Federação, Bertha Lutz, a diretora da EAN destacou uma delegação de quatro enfermeiras para representar a escola no $3^{\circ}$ Congresso Nacional Feminino a se realizar de 20 a 30 de setembro de 1936, no Automóvel Club do Brasil. Centro de Documentaçăo da EEAN, cx 58, doc.147, 1936.

44 Como nasceu a SOS (Serviço de Obras Sociais) Sociedade Civil de Amparo aos Necessitados. Seu Programa, Suas lutas. História da SOS. 19 p.

${ }^{45}$ como evidencia um memorando de Ethel Parsons intitulado "Estado atual da Escola de Enfermeiras Anna Nery e vantagens de seu desenvolvimento futuro como escola universitária". Centro de Documentaçäo da EEAN, cx 30, doc.19, 1931.

${ }_{46}$ E tanto assim que a Associação Brasileira de Enfermeiras Diplomadas deliberou agraciar Bertha Lutz, lider desse movimento, com o titulo de sócia honorária, pelo "trabalho que realizou em 1937 para colocar a Escola Anna Nery na Universidade do Brasil" (Carvalho, 1992, p.63-64).

47 lei 452, de 5 de julho de 1937.

${ }^{48}$ Centro de Documentação da EEAN, cx 64, doc.92, 1937.

49 Centro de Documentação da EEAN, cx 62, doc. 46, 1937.

${ }^{50}$ Centro de Documentaçāo da EEAN, cx 62, doc.45, 1937.

5t e em 1939, a irmã Matilde Nina, formada pela Escola Carlos Chagas, funda no Rio de Janeiro uma Escola de Enfermeiras Católicas (Teixeira et alii, 1998, p.6, 15 e 18).

52 Centro de Documentação da EEAN. Arquivo de História Oral. Depoimentos de ex-alunas. 
ABSTRACT: This report belongs to the research line "The professional practice and identity building of the Brazilian Nurse", developed by a group registered at the CNPq and Research Center of History of Brazilian Nursing (Nuphebras) of the School of Nursing Anna Nery, Federal University of Rio de Janeiro. The objectives of this study are: correlate the institutional changes of Nursing in the Brazilian society of that time to the accentuated political and economical transition of the country; analyze the effects of those institutional changes in the nurse's labor market and in the characteristics of nursing practice: discuss the new articulation forms of nursing with other social practices inside the area of health. National public health nursing, in order to accompany the enlargement of the bureaucratic State, expanded and modified. At the same time, in a context of a protectionist policy to the worker, an incentive policy to the opening of new, public and private hospitals, was developed, although Nursing services of those institutions were not organized according to the patterns that characterized the modem Nursing. Thus, the practice of Nursing in the 30's is characterized as the beginning of the transition of a model of urban public health to a model of hospital assistance.

KEYWORDS: history of nursin, public health nursing, health Policy

RESUMEN: Este relatorio se incluye en la linea de pesquisa "La práctica profesional y la formación de identidad de la enfermeria brasilera", desarrollada por un grupo registrado en el CNPQ y en el núcleo de Pesquisa de História de la Enfermeria Brasilera (NUPHEBRAS) de la Escuela de Enfermeria Anna Nery, Universidad Federal de Rio de Janeiro. Los objetivos de este estudio son: relacionar los cambios institucionales de la enfermeria en la sociedad brasilera de la época a la acentuada transición politica del pais; analisar los efectos de estos cambios en el mercado de trabajo de la enfermera y en las caracteristicas de la práctica de la enfermeria; discutir las nuevas formas de articulación de la enfermeria con otras prácticas sociales dentro del área de la salud. La enfermeria, de la salud pública nacional, se modificó y se expandió para acompañar la ampliación del estado burocrático. Al mismo tiempo, en un contexto de politica de protección al trabajador, desarrolló una politica de incentivo a la apertura de hospitales públicos y privados, a pesar de que los servicios de enfermeria de estas instituciones no fuesen organizados según los padrones que caracterizan la enfermeria moderna. Asi, la práctica de enfermeria en la década del 30 se caracteriza como el inicio de la transición de un modelo de salud pública urbana para un modelo de asistencia hospitalar.

PALAVRAS LLAVE: historia de la enfermeria, enfermeria de salud pública, politica de salud.

\section{BIBLIOGRAFIA}

BAPTISTA, Suely de Souza ; BARREIRA, leda de Alencar. A luta da enfermagem por um espaço na universidade. Escola de Enfermagem Anna Nery / UFRJ, 1997. 194 p.

BARREIRA, leda de Alencar. Contribuiçāo da História da Enfermagem Brasileira para o desenvolvimento da profissão. Conferência. Núcleo de Pesquisa de História da Enfermagem Brasileira (Nuphebras) Escola de Enfermagem Anna Nery / UFRJ (cópia xerográfica). $39 \mathrm{p}$.

BARREIRA, leda de Alencar. Os 75 anos da EEAN: politica internacional, cotidiano e história. Escola Anna Nery, R.Enferm., Rio de Janeiro, v. 2 n. 1/2, abr./set. 1998. Editorial.

BARREIRA, leda de Alencar. A enfermeira ananéri no pais do futuro. Rio de Janeiro: Editora da UFRJ, 1997.

CAMPOS, Gastão Wagner de Souza. A saúde pública e a defesa da vida. Sāo Paulo: Hucitec, 1994.

CARVALHO, Anayde Corrêa. Associação Brasileira de Enfermagem: documentário (1926-1976). Brasilia, 1976.

COELHO, Cecilia Pecego. Escola de Enfermagem Anna Nery: sua história, nossas memórias. Rio de Janeiro: Cultura Mèdica, 1997, $224 \mathrm{p}$.

COOK, Edward. The life of Florence Nightingale. New York: The Mac Millan Co., 1942.

ESTADO DA GUANABARA. Secretaria de Estado de Saúde. Superintendência de Serviços Médicos. 
Assistência Pública: Guanabara, 80 anos de história. Rio de Janeiro, SES/GB, 1972.

FAUSTO, Boris. História do Brasil. 2.ed. São Paulo: Editora da Universidade de São Paulo, 1995.

FONSECA, Adelina Z da. Plano de uma escola de serviço social e suas finalidades. Rio de Janeiro, Annaes de Enfermagem, v.5, n.9, mai., 1937. p.24-25.

FONTENELLE, J.P. A enfermagem de saúde pública: sua criaçăo e desenvolvimento no Rio de Janeiro.

Rio de Janeiro: Canton \& Reile Grảf., 1941. 48 p.

FRAENKEL, Edith de Magalhäes. O Serviço Social. Annaes de Enfermagem, Rio de Janeiro, 'v.5, n. 10, p.5-7. set. 1937

HADDOCK-LOBO, Rachel. Escola Anna Nery, Relatório Narrativo, setembro de 1932.

HOCHMAN, Gilberto. Regulando os efeitos da interdependência sobre as relaçōes entre saúde pública e construção do Estado (Brasil, 1910-1930) Estudos Históricos. Rio de Janeiro,v. 6, p.40-61, 1993.

HORTA, José Silvério B. O hino, o sermão e a ordem do dia: a educação no Brasil. Rio de Janeiro: ed. UFRJ, 1994.

LIMA, Izaura Barbosa. Enfermagem na organização sanitária federal. Anais de Enfermagem,v. 5 n.1,p.8493, jan. 1952.

LIMA, Izaura Barbosa. Desenvolvimento da Enfermagem no Brasil. Rio de Janeiro: Fundaçäo Ensino Especializado de Saúde Pública, 1968 (cópia xerográfica).

MAGALHĀES, Mário. A politica de saúde pública no Brasil nos últimos 50 anos. Conferência. Simpósio sobre Politica Nacional de Saúde. Anais... Câmara dos Deputados. Brasilia: Comissão de Saúde. p.199-215.

MEDEIROS, Ana Ligia ; HIRST, Mônica. Bibliografia Histórica: 1930-1945.Brasilia: Editora da Universidade de Brasilia, 1982.

OLIVEIRA, Jaime A. de Araujo: TEIXEIRA, Sonia M. Fleury. (Im)previdência Social: 60 anos de história da previdência no Brasil. Petrópolis: Vozes / Abrasco, 1985.

PULLEN, Bertha. Status legal da enfermagem. Rio de Janeiro, Annaes de Enfermagem, v.5, n.11, p.30-34, dez. 1937.

Obrigações legais da enfermeira em relação ao médico e ao doente. Rio de Janeiro, Annaes de Enfermagem, v.5, n.11, p.4-8 mar. 1938.

Pontos essenciais para um serviço de enfermagem hospitalar adequado. Rio de Janeiro, Annaes de Enfermagem, v.5, n.13/14, p.54-60, jul./set., 1938.

RIBEIRO, Lourival. Hospitais e Casas de Saúde. In: O Barão do Lavradio e a Higiene no Rio de Janeiro. Rio de Janeiro: ed. Itatiaia, 1992. p.199-226.

RODRIGUES, Amália Pereira da Silva. A vida de Edith de Magalhães Fraenkel.1985 (cópia xerográfica) 93p.

ROMANELLI, Otaiza de Oliveira. História da educação no Brasil (1930/1973). 9. ed. Petrópolis: Vozes, 1987.

SANTOS, Tânia Cristina Franco. A câmera discreta e o olhar indiscreto: a persistência da liderança norte-americana no ensino da enfermagem na capital do Brasil (1928-1938). Rio de Janeiro,1996.229p. Tese (doutorado). Escola de Enfermagem Anna Nery / UFRJ.

SAUTHIER, Jussara. A Missão de enfermeiras norte-americanas na capital da república (1921-1931)Rio de Janeiro,1996.258p.Tese(Doutorado). Escola de Enfermagem Anna Nery / UFRJ.

TABORDA, Rosaly. Enfermagem deficiente. Rio de Janeiro, Annaes de Enfermagem, v.5, n.9, p. 46, mai. 1937.

TABORDA, Rosaly. Bons Exemplos. Rio de Janeiro, Annaes de Enfermagem, v.5, n.11,p.42-44 dez. 1937.

TEIXEIRA, Carmem Luisa dos Santos; BAPTISTA, Suely de Souza; CAVALCANTI, Rosa Maria N.T.; SAUTHIER, Jussara. Alunas religiosas na Escola de Enfermagem Anna Nery, nas décadas de 20 a 40. Rev. Esc.Anna Nery, Rio de Janeiro, v.2, n.1/2, abr./set, 1998. 